\title{
Effect of pulsating disintegrating airflow on electric arc depositing
}

\author{
Mohammad E. Matarneh*, Vyacheslav Royanov** and Irina Zakharova** \\ *Al-Balqa Applied University, Al-Huson University College Department of Mechanical Engineering, Al-Huson-Irbid, Jordan. P.O. Box 50, \\ Irbid, Jordan \\ **Department of Automation and Mechanization of Welding Production, State Higher Educational Institution, Priazovskiy State Technical \\ University, Mariupol, Ukraine \\ *Corresponding Author: m.matarneh@bau.edu.jo
}

Submitted: $12 / 03 / 2020$

Revised: $\quad 06 / 12 / 2020$

Accepted: 15/12/2020

\begin{abstract}
To limit the losses in sprayed metal in the process of electric arc deposition, the disintegrating airflow is pulsated. In this work, the effect of changing the pulsation frequency was studied on the process performance, mainly, the efficiency of metal removal and rate of deposition. Additionally, the bonding strength of the resulting sprayed metal was evaluated at different pulsation frequencies. The application of air pulsations increases the productivity and efficiency of sprayed material by increasing the efficiency of material used up to $30 \%$ and enhancing the rate of deposition up to $32 \%$, at a frequency range $70-80 \mathrm{~Hz}$. Moreover, at the optimum frequency of air pulsations, the bond strength increased up to $69 \%$, measured by Steffensen's dowel method. The results found in this work will allow for more rational usage of the electrical arc energy and material.
\end{abstract}

Keywords: Arc deposition; Pulsating jet; Deposition of coatings; Bond strength.

\section{INTRODUCTION}

In the process of arc deposition, intensive oxidation of the applied (i.e., sprayed) metal takes place. This phenomenon, which is attributed to the presence of oxygen in the air stream, will lead to significant losses of the alloying element (as oxides) present in the molten coating (Khasui \& Marigaki, 1985). Researchers have investigated this observation. Khasuiand Marigaki (Khasui \& Marigaki, 1985) showed that, compared to flame deposition, arc deposition of metal resulted in a clear decrease in the content of alloying elements in the resultant coating. Oxidation is also capable of reducing the carbon content in the sprayed coating when using arc deposition of carbon steel wire compared to the original content of the sprayed metal (Khasui \& Marigaki, 1985). Table 1 shows details on these findings. 
Table 1. Change in the content of elements in steels during flame and arc spraying (Khasui \& Marigaki, 1985).

\begin{tabular}{|c|c|c|c|}
\hline \multicolumn{2}{|c|}{ Element in sprayed metal (\%) } & \multicolumn{2}{c|}{ Content of elements in a coating (\%) } \\
\cline { 3 - 4 } & 0.41 & Arc Deposition & Flame Deposition \\
\hline \multirow{3}{*}{ Manganese } & 0.5 & 0.30 & 0.35 \\
\cline { 2 - 4 } & 0.52 & 0.30 & 0.48 \\
\cline { 2 - 4 } & 0.60 & 0.36 & 0.46 \\
\cline { 2 - 4 } & 0.23 & 0.46 & 0.55 \\
\cline { 2 - 4 } & 0.23 & 0.14 & 0.20 \\
\cline { 2 - 4 } & 0.27 & 0.14 & 0.21 \\
\hline \multirow{3}{*}{ Silicon } & 1.18 & 0.22 & 0.27 \\
\hline
\end{tabular}

Change in carbon content during arc metallization with carbon steel wire

\begin{tabular}{|c|c|}
\hline Carbon content in sprayed material (wire), C \% & Carbon content in sprayed material (wire), C \% \\
\hline 0,91 & 0,39 \\
0,69 & 0,16 \\
0,30 & 0,13 \\
0,07 & 0,04 \\
\hline
\end{tabular}

In order to reduce the effect of oxygen during coating deposition, the Department of Automation and Mechanization of Welding Production in Priazovskyi State Technical University has developed the method of electric arc depositing through the use of pulsating disintegrating airflow mechanism (Royanov \& Bobikov, 2015).

The principle of this technique, the equipment used to provide the desired disintegrating through pulsations the flow of air, shape/duration of the pulses, and effect of a flow on a sprayed material are all well documented in the literature(Royanov \& Bobikov, 2015; Royanov et al., 2014; Royanov et al., 2019).

The effect of disintegrating pulsating airflow has been studied before on a group of applications that include: the structure and micro-hardness of the resulting coating, as a mechanism to reduce the effect of the presence of oxygen in the air surrounding the liquid metal of electrodes, and on metal mass transfer, all of which are presented in works (Royanov et al., 2017; Royanov et al., 2017; Royanov et al., 2014).

However, there is no data on the effect of disintegrating pulsating airflow on the performance and effectiveness of the flow of sprayed coating material during electric arc deposition, and the resulting coat bonding strength to a base that has been applied to. One of the main factors controlling this process is the frequency of the pulsations. The work presented in this paper provides the results of studying the effect of pulsation frequency of the disintegrating airflow on the aforementioned characteristics, at constant levels of electrode's arc energy, and fixed operational conditions related to wire material and size, and electrode current and voltage.

\section{MATERIALS AND METHODS}

\section{Air Pulsator}

In order to provide the required changes in air pulsation frequency while applying coating deposition, and air pulsation setup is used. The setup includes a controlled AC motor that provides the drive to produce the desired airflow along with a pulsating valve that controls the required frequency is used. Figure 1 shows a schematic of the used air pulsator system. 




Figure 1. Schematic diagram of air pulsator.

\section{Evaluating the effect of pulsation frequency on the material deposition.}

The effect of air pulsation frequency on the process of disintegrating pulsating airflow of coating deposition can be presented by the subsequent analysis.

The rate of deposition during the coating process can be evaluated by the following equation:

$$
N=\frac{P_{\text {coat }}}{t_{c}}
$$

where $N$ is the rate of deposition $\left(\mathrm{kg} / \mathrm{hr}\right.$.); $t_{c}$ is the time required for the formation of a coat (hr.); and $P_{\text {coat }}$ is the weight of deposited coating during a specific period of time $\left(t_{c}\right)$ under a given pulsation frequency $f(\mathrm{~kg})$

The effect of pulsation frequency on the efficiency of the coating of a sprayed material can be determined according to the following equation:

$$
\gamma=\frac{P_{\text {coat }}}{P_{\text {spr }}}
$$

where $g$ is the coating efficiency, and $P_{s p r}$ is the weight of the two sprayed electrodes $(\mathrm{kg})$.

In order to determine the values of $N$ and $g$, the weight of both the sprayed material (applied) and the formed coating at time $t$ were experimentally determined. The weight of the sprayed material can be evaluated by the following equation assuming that the two electrodes are cylindrically shaped:

$$
P_{s p r}=\left(\pi \cdot d^{2} / 2\right) \cdot l_{a v} \cdot \rho
$$

where $d$ is the diameter of sprayed electrodes $(\mathrm{cm}) ; l_{a v}$ is the average length of the two sprayed electrodes $(\mathrm{cm} \pm$ $0.01 \mathrm{~cm})$; and $r$ is the density of the metal in the two sprayed electrodes, for steel equals $\left(7.6 \mathrm{~g} / \mathrm{cm}^{3}\right)$.

In this work, the effect of air pulsation frequency on the process of disintegrating pulsating airflow of coating deposition is evaluated by assessing changes in the performance of the coating process, mainly the rate of deposition and the efficiency of the process.

Change in the performance related to deposition rate can be calculated according to the following equation:

$$
N_{f}=\frac{N_{\max }-N}{N} \times 100 \%
$$

where $N_{f}$ is relative change in deposition rate at a given frequency (\%); $N$ is the deposition rate without pulsation $(\mathrm{kg} / \mathrm{h})$; and $N_{\max }$ is the maximum deposition rate with pulsation $(\mathrm{kg} / \mathrm{h})$. 
The change in material usage efficiency (amount deposited) can be calculated according to the following equation:

$$
\gamma_{f}=\frac{\gamma_{\max }^{f}-\gamma}{\gamma} \times 100 \%
$$

where $g_{f}$ is the relative change in the efficiency of the process at a given frequency; and $g$ is the efficiency of the process without pulsation; and $\gamma_{\text {max }}^{f}$ is the efficiency of the process with pulsation.

For this part of the work, values of $P_{c o a t}, P_{s p r}$, and time were measured and calculated at a frequency between 20 to $120 \mathrm{~Hz}$. For this application, the wire used was Sv-08A (European Union analogue for S2), with a diameter of $2 \mathrm{~mm}$. The current used was $200 \mathrm{~A}$, with a voltage of $30 \mathrm{~V}$. The maximum air pressure was $5 \mathrm{MPa}$.

\section{Evaluating the effect of pulsation frequency on bond strength.}

In order to evaluate the effect of air a pulsation frequency on the resulting bond strength of an applied coating, Steffensen's dowel sample method was used (Royanov and Bobikov; 2015). The schematic diagram of the experiment and the components of the device are shown in Figure 2.

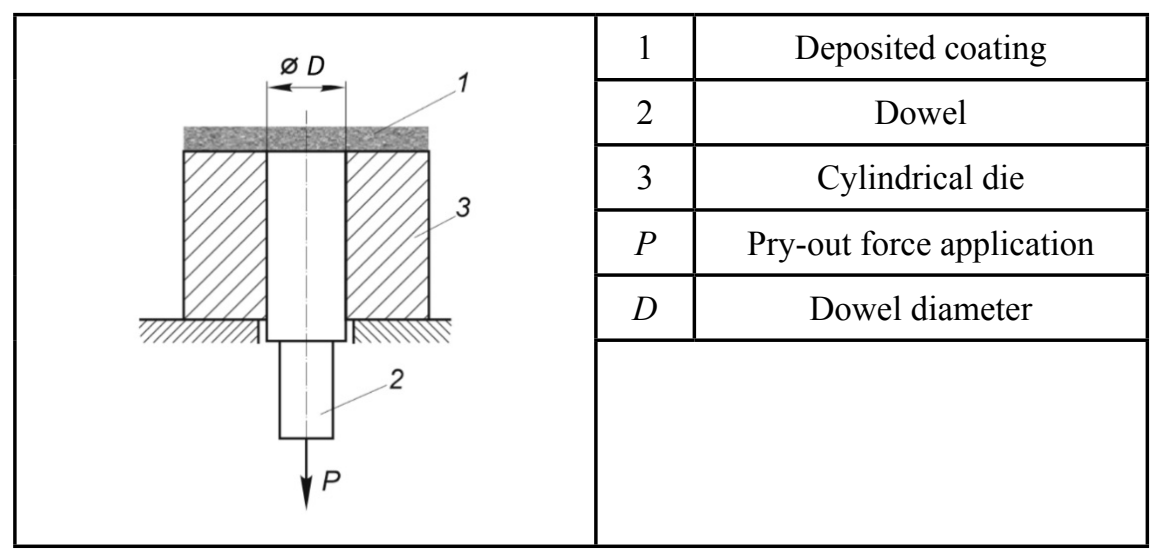

Figure 2. Schematic diagram of the experiment setup and components of the device used in Steffensen's dowel sample method (Royanov and Bobikov; 2015).

The method mainly works by measuring the bond strength of a coating when applied to a base. For this purpose, the cylindrical dowel is set into a cylindrical die, and the coating is deposited on the base under conditions set. The dowel is pried out, while the amount of force applied is monitored with a dynamometer.

For this part of the work, values for the frequency was changed from 40 to $120 \mathrm{~Hz}$. For this application, the wire used was Sv-08A (European Union analogue for S2), with a diameter of $2 \mathrm{~mm}$. The current used was $200 \mathrm{~A}$, with a voltage of $30 \mathrm{~V}$. The maximum air pressure was $5 \mathrm{MPa}$. The standard reported bond strength for the material used in the analysis (dowel sample) is reported as 27.3 MPa (Bezborodov, 2016; Tamargazin et al., 2010).

\section{RESULTS AND DISCUSSION}

\section{Evaluating the effect of pulsation frequency on the material deposition.}

In this part, values for $P_{c o a t}, P_{s p r}$, and time were evaluated five times at each one of the pulsation frequencies $(20$ to $120 \mathrm{~Hz}$ ). Figure 3 shows the effect of changing the frequency of air pulsations on the efficiency of material deposition (coating efficiency) and deposition rate. 

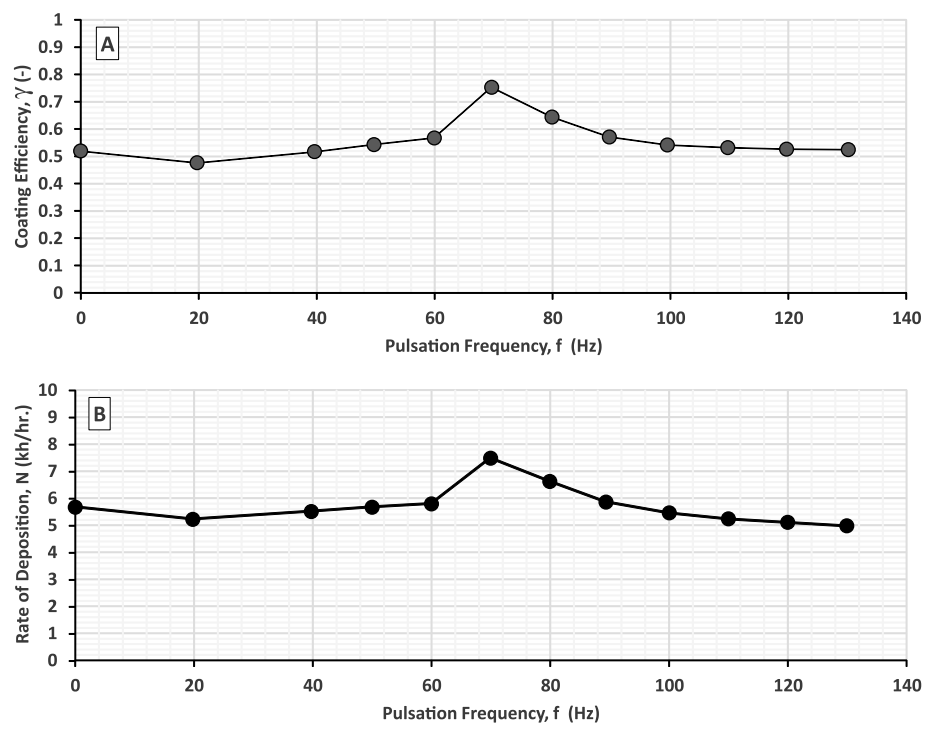

Figure 3. Effect of pulsation frequency on the efficiency of material coating (a) and rate of deposition (b).

Values for the coating efficiency and deposition rate were calculated using Equations 1 and 2. As it can be seen in Figures 3A and 3B, for the case with no pulsation the efficiency and rate were 0.52 and $5.7 \mathrm{~kg} / \mathrm{hr}$., respectively. The effect of air pulsation was not apparent on both the coating efficiency and the deposition rate until the values of the frequency applied reached $60 \mathrm{~Hz}$, with values of both reaching $0.52 \pm 0.04$ and $5.56 \pm 0.25 \mathrm{~kg} / \mathrm{hr}$., for the coating efficiency and deposition rate, respectively. Values of both aforementioned performance parameters sharply increased in the frequency range between 60 and $90 \mathrm{~Hz}$, reaching values of 0.75 and $7.49 \mathrm{~kg} / \mathrm{hr}$. for the coating efficiency and deposition rate, respectively. Both values were reduced after $90 \mathrm{~Hz}$, reaching levels similar to those measured in the initial frequency's, for coating efficiency $(0.53 \pm 0.01)$, and slightly lower in the deposition rate $(5.19 \pm 0.20 \mathrm{~kg} / \mathrm{hr}$. $)$.

Enhancements on both the efficiency of coating material usage and deposition rate were evaluated from Equations 4 and 5. Figure 4 shows the effect of changing the air jet pulsation frequency on the relative change in both aforementioned parameters.


Figure 4. Effect of pulsation frequency on the enhancement of the relative change in the usage efficiency of material coating (a) and the relative change in the rate of deposition (b). 
The effectiveness of the process is clearly seen in the previous figures. Increasing the air pulsations increased the efficiency of the usage of coating material to almost $30 \%$, while the rate of material deposition was enhanced by $31.8 \%$. These enhancements were incremental until air pulsation frequency reached a value of $70 \mathrm{~Hz}$, after which relative changes dropped, as the frequency was increased. Leading to conclude that the effectiveness of the process is reduced after the air pulsation frequency values of $90 \mathrm{~Hz}$. This is clearly seen in the data found in Figure 3, where no changes in the usage of coating material efficiency or deposition rate were found beyond this frequency.

The main observations shown above can be explained by examining the behavior of the molten metallic material during the process. In this work, a relatively high electrode's arc energy is used and remained constant during all experiments. This insured that the rate of transfer of the metallic material resulting from arc pulsation remains constant.

As the metal is melted from the electrode, droplets are formed and began to accumulate on the sidewall of the electrode. These droplets are under the effect of two forces; surface tension force and electromagnetic force. Liquid molten metal formed on the electrode, affected by the electromagnetic force, will be pushed into the flow stream of the pulsating air, resulting in the disintegration of the formed molten metal.

At lower frequencies of air pulsations (up to $30 \mathrm{~Hz}$ ), the molten liquid metal will accumulate on the surface of the electrode, due to the lack of sufficient air to achieve any enhancements of the disintegration process. This will lead to material build-up on the electrode itself, and eventually, cause a short circuit preventing the generation of the electric arc. Under a medium frequency $(70$ to $80 \mathrm{~Hz}$ ), the period of time for the formation of liquid metal on the sidewalls of the electrode coincides with the impulse frequency of disintegrating airflow. This manages to remove the molten metal effectively; as the metal is molten and formed on the electrode sidewall, it will be removed and applied. By its turn, this allowed for an enhanced rate and efficiency for the process.

When the frequency of air pulsations is increased, air removes and disintegrate the molten metal as it is being formed on the electrode. Thus, preventing any further enhancements in the accumulation of the molten metal on the electrode. Reducing the performance to levels achieved at levels of lower frequencies.

\section{Evaluating the effect of pulsation frequency on bond strength.}

The Steffensen's dowel method was used to evaluate enhancements in coating strength brought by changes in the frequency of applied disintegrating air pulsations. Figure 5 shows the die and dowel before and after the application of the coating.

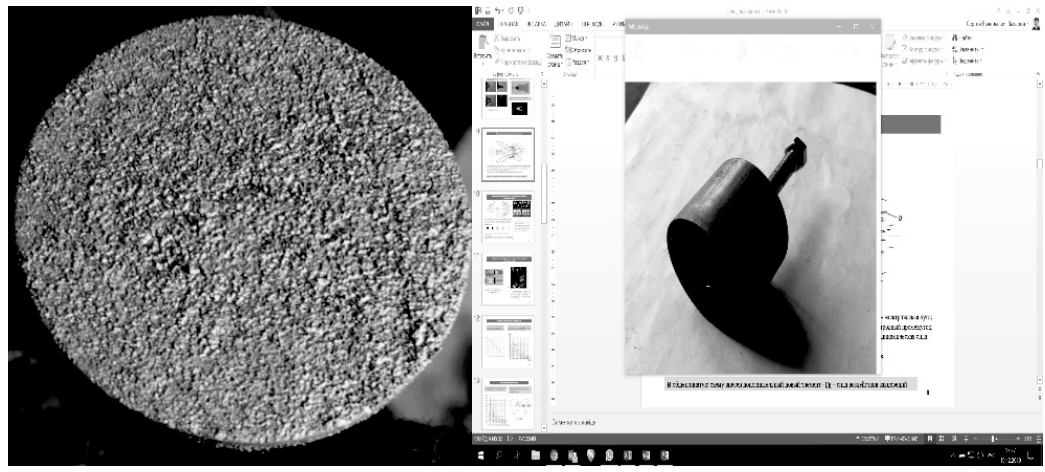

Figure 5. The coating deposited on the die and dowel applying the method of arc metallization with pulsating disintegrating air.

The bond strength was measured for coatings at different frequency values. Five tests were performed at each frequency. Figure 6 shows the effect of changing air pulsation frequency on the resulting pray-out force in Steffensen's dowel method. 
As seen in the figure, the pray-out required force increased as the frequency of air pulsations increased. Increasing from the base level of 27.3 MPa to almost 46.1 MPa, at a frequency of $70 \mathrm{~Hz}$ (an enhancement of $69 \%$ ). This can be attributed to the increase in metal removal efficiency (from the electrode) and deposition rate observed in the previous section, achieved at this level of air pulsation frequency.

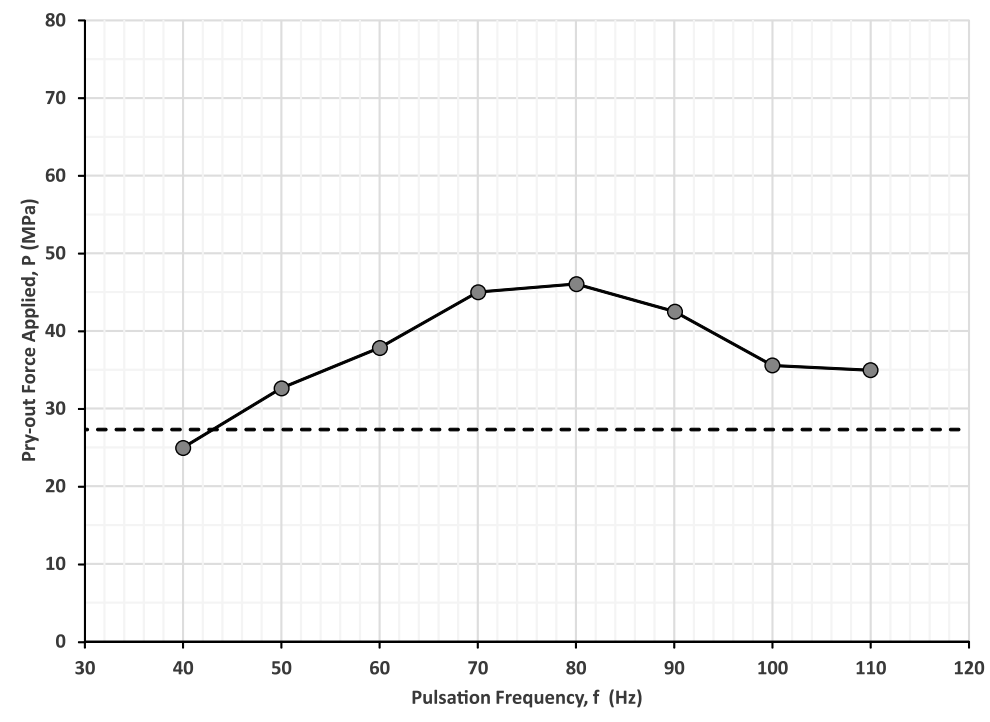

Figure 6. Effect of changing air pulsation frequency on pray-out bond strength.

The dashed line represents the standard bond strength of the dowel sample (Bezborodov, 2016; Tamargazin et al., 2010).

Improvements in pray-out strength dropped as frequency increased, to the same reasons that forced a drop in the efficiency and deposition rate, explained in the previous section. However, pray-out strength did not drop to initial levels, rather it stabilized to $35.2 \pm 0.42 \mathrm{MPa}$, which is higher than the reported base level by almost $30 \%$.

\section{CONCLUSIONS}

The study discussed here studied the effect of changing the pulsation frequency of the disintegrating airflow on the performance and effectiveness of the flow of sprayed coating material during electric arc deposition, and the resulting coat bonding strength. From what has been presented, the following can be concluded:

1. Application of a pulsating airflow when performing electric arc deposition helps increase the productivity and efficiency of sprayed material by increasing the efficiency of material used and enhancing the rate of deposition, resulting in a more rational usage of the electrical arc energy, and material.

2. Enhancements brought by the increase in the frequency of air pulsation will reach a maximum limit, at the conditions of these experiments, which were found to be $30 \%$ increase in the coating efficiency and almost $32 \%$ increase in deposition rate, at $70-80 \mathrm{~Hz}$. This limit can be surpassed if the electrical arc energy is increased.

3. At the optimum frequency of air pulsations, the bond strength increased up to $69 \%$, measured by Steffensen's dowel method. Beyond that point, a lesser degree of enhancement is reached (30\%) as the frequency increased. 


\section{REFERENCES}

Bezborodov, I.A. 2016. Regulations on adhesion strength of sprayed coatings for restoration of crankshaft necks of auto-tractor internal combustion engines. Scientific and technical center detonation, 3: 25-30.

Hasui, A., \& Marigaki, O. 1985. Buttering and spraying. Machine-building, Moscow, pp. 240.

Royanov, V.A., Bobikov, V.I. 2015. Device for electric arc metalization with pulsating flow mode of the air-spraying flow. Welding manufacturing, 4: 12-15.

Royanov, V., Zakharova, I., Lavrova, E. 2017. Development of properties of spray flow and nature of pressure distribution in electric arc metalization. Eastern-European Journal of Enterprise Technologies, 6/5 (90):41-49.

Royanov, V.A., Zakharova, I.V., Kryuchkov, N.S. 2019. Reduction of the oxygen influence on liquid metal at electroarc spraying by a pulsating spraying airflow. World Sience, 5(45): 13-21.

Royanov, V.A., Zakharova, I.V., Kryuchkov, N.S. 2017. Research of the influence of spraying device structures on the quality of the sprayed layer. SIHE "PSTU”, Mariupol. T2: 86-87.

Royanov, V, Zakharova, I., Kriuchkov, M., Chigarev, V. 2020. Investigation of factors, determining dispersity of coating particlesat arc spraying with pulsating spraying flow //World science. 6(58): 10-20.

Royanov, V.A., Zusin, V.Y., Samotugin, S.S., Zakharova, I.V. 2014. Defects Control and Quality Management in Welding and Related Technologies. Training Manual. Quality of sprayed coatings. SIHE”PSTU” Mariupol. Pp. 390

Tamargazin, A.A., Lopata, L.A., Brusilo, Y.V., Dovzhuk, S.A. 2010. The influence of electroarc spraying process factors on structural formation and properties of coatings. Equipment in agricultural production, sector-specific machine-building, automatization, 23: 287-297.

Zakharova, I. 2020. The effect of a pulsating spraying jet on the volume of air that comes in contact with metal electrodes at arc metallization. Technium 2: 139-147. 